\title{
Strengths-based Lean for Five Years - Experiences from Everyday Operations
}

\author{
Jørgensen, Rasmus
}

Published in:

A I Practitioner

Publication date:

2015

Document Version

Publisher's PDF, also known as Version of record

Link back to DTU Orbit

Citation (APA):

Jørgensen, R. (2015). Strengths-based Lean for Five Years - Experiences from Everyday Operations. A I Practitioner, 17(4), 45-51.

\section{General rights}

Copyright and moral rights for the publications made accessible in the public portal are retained by the authors and/or other copyright owners and it is a condition of accessing publications that users recognise and abide by the legal requirements associated with these rights.

- Users may download and print one copy of any publication from the public portal for the purpose of private study or research.

- You may not further distribute the material or use it for any profit-making activity or commercial gain

- You may freely distribute the URL identifying the publication in the public portal

If you believe that this document breaches copyright please contact us providing details, and we will remove access to the work immediately and investigate your claim 
International Journal of Appreciative Inquiry

\section{November 2015}

Volume 17 Number 4

ISBN 978-1-907549-25-0

do) dx.doi.org/10.12781/978-1-907549-25-0

\section{Al Practitioner}

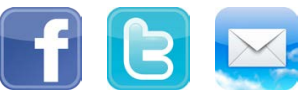

www.aipractitioner.com/subscriptions

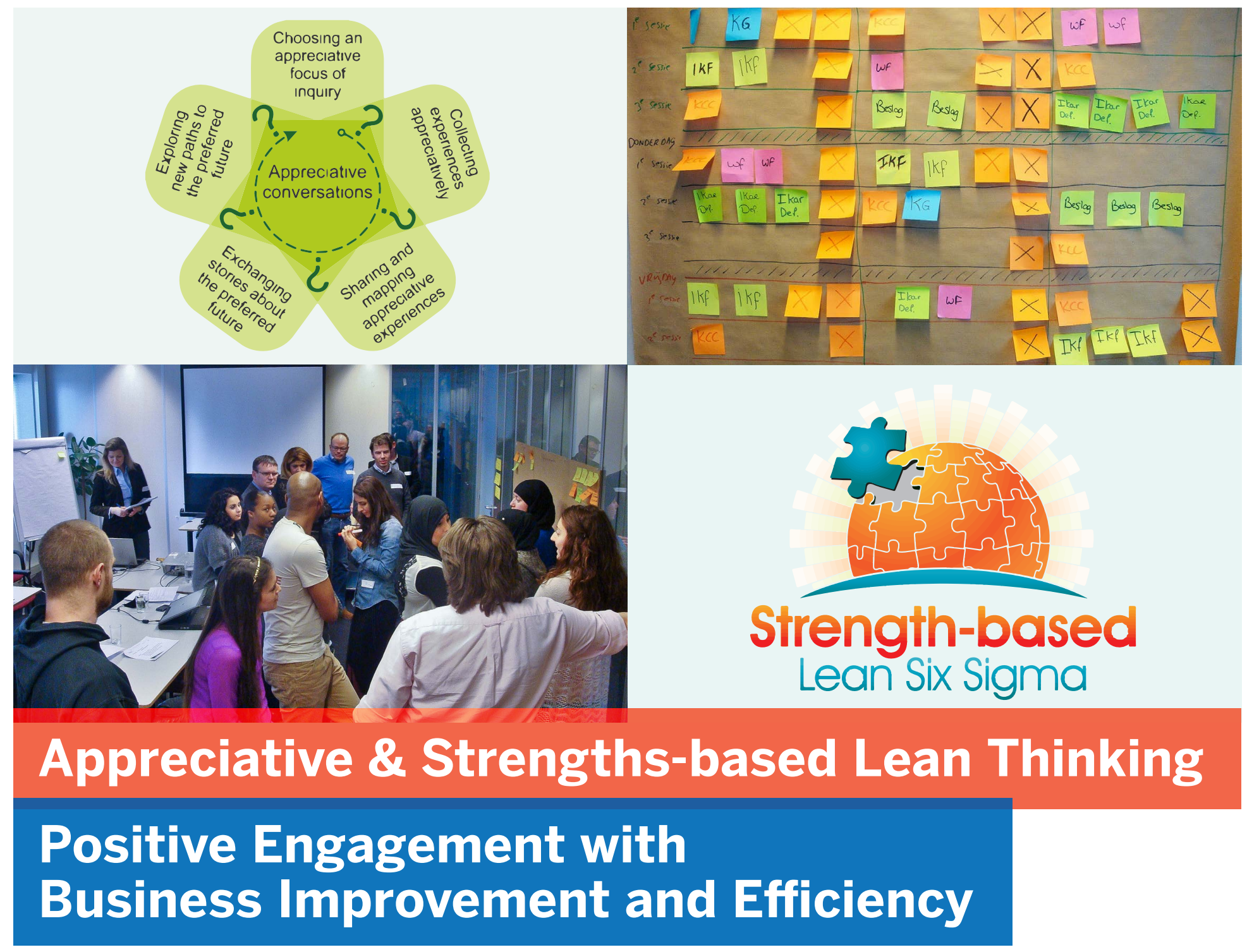

Edited by

David Shaked and Nicolas Stampf

Sponsored by

Instituut voor Interventiekunde

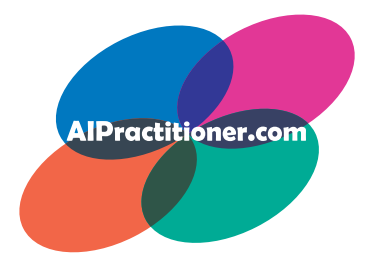




\section{Appreciative \& Strengths-based Lean Thinking: Positive Engagement with Business Improvement and Efficiency}

\section{Inside this issue}

\section{Welcome to November 2015 issue of Al Practitioner}

This issue details what makes process improvement engaging and resourceful, and creates something new that is better and more powerful than simply adding the two fields together.

In "Sustainable OD as an Issue Centric Approach”, Danielle P. Zandee sets out four premises of sustainable OD.

In Research Review \& Notes, Jannie

Pretorius from South Africa shows how studying the positive core of exceptional individuals has been applied in higher education, while Al Resources focuses on ways Al can help evolve the use of Lean Thinking in businesses and organisations.

From 2016, Al Practitioner will be published by the Instituut voor Interventiekunde (Institute for Intervention Studies, www. instituutvoorinterventiekunde.nl) in Amsterdam, a school of Appreciative
Interventionism and place to become an Al practitioner, master practitioner or meta practitioner. Founded by Wick van der Vaart, it has many ideas for developing Al Practitioner and I wish them all success. Very many thanks to everyone who helped me develop a simple email newsletter into the current international journal.

Anne Radford

Editor, Al Practitioner
4 Appreciative \& Strengthsbased Lean Thinking: Positive Engagement with Business Improvement and Efficiency

Editors: David Shaked and Nicolas Stampf

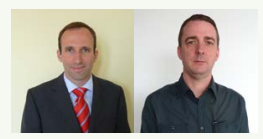

\section{Appreciative Inquiry Lean} A New Route to Success for Team Leaders

Jacqueline Bustos Coral, Juan Pablo Ortiz Jiménez and Kaj Voetmann

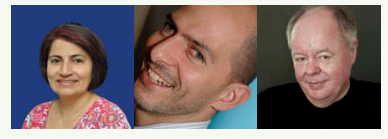

9 Feature Choice Sustainable OD as an Issue-centric Approach

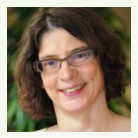

Danielle Zandee

30 Lean with a Solution-focused Twist

A Process of Continuous Improvement

Karla Stonham and Brenda Zalter-Minden

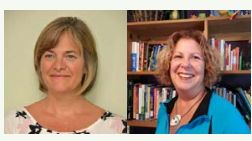

17 Interview with an Operations Director

Accelerated Business Improvement through Strengths-based Lean Six Sigma

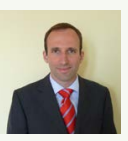

David Shaked

38 Strengths-based Kaizen Blitz in a Public Organisation

Theo van den Eijnden and Martijn Molenaar

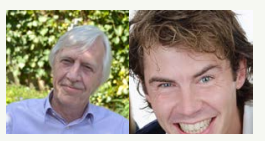


45 Strengths-based Lean for Five Years

Experiences from

Everyday Operations

David Hansen and

Rasmus Jørgensen
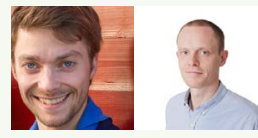

52 KISS: Keep Improving Simple and Straightforward

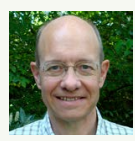

58 A Human Performance Architecture Framework for Integrating Strengths-based Approaches to Organizational Change in a Geographically Distributed Organization

Peter Baverso
64 Appreciative Inquiry Research Review \& Notes Appreciating Exceptional People in South Africa: Developing a Framework and Applying it in Higher Education

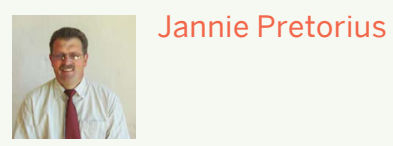

71 Appreciative Inquiry Resources

Resources for combining $\mathrm{Al}$ and Lean Thinking to find a strengthsbased model for improving organisations

Matthew R. Moehle, Roopa Nandi and Hardik Shah
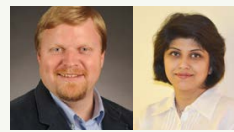

77 About the February 2016 Issue

How Has Appreciative Inquiry Lived Up to its Promises? What Will the Future of Appreciative Inquiry Look Like?

Editors: Robbert Masselink and Wick van der Vaart

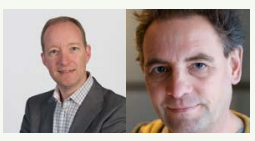

78 About the sponsor of this issue Instituut voor Interventiekunde

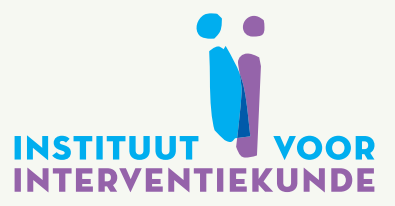

79 Advertisements

Al Practitioner 2015

Research, Review and Notes

Feature Choice
80 IAPG Contacts and AI Practitioner Subscription Information 

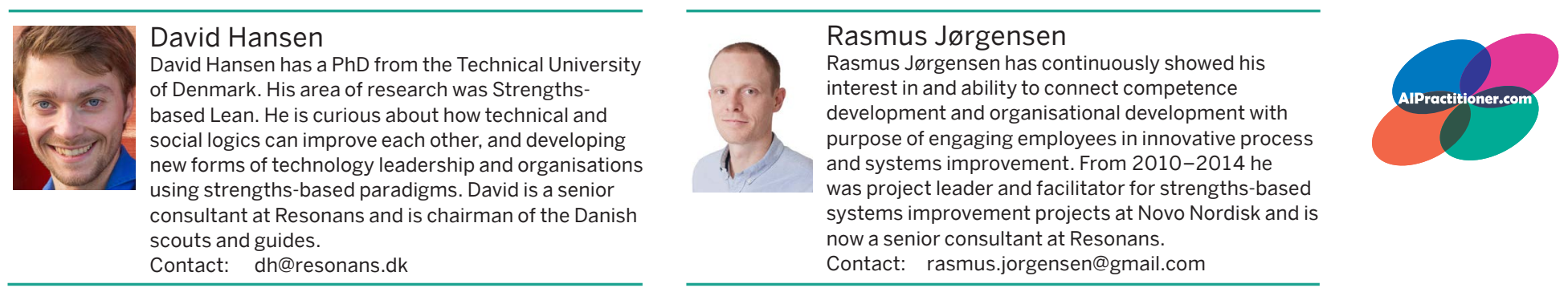

\section{Strengths-based Lean for Five Years \\ Experiences from Everyday Operations}

The need for creating more value with fewer resources is apparent in most organisations. For decades, the discussion has been whether to apply rational logics and improvement tools or to apply social logics and empowering change methods. However, pioneering practitioners have embraced the best of both worlds to simultaneously develop people and technical systems with the insights from Lean thinking and the strengths-based paradigm. We present a look into such a pioneering manager's everyday operations after five years of practising Strengths-based Lean.
It is a beautiful morning; a little bit of snow and a clear sunny sky. We arrive at the factory and put on visitors' clothing. Everything needs to be clean, and there are standardised procedures to ensure good manufacturing practices are followed and compliance with the food and drug authorities needed to produce medical devices. We have just entered Novo Nordisk's Danish manufacturing plant for the world's top-notch insulin pen. Around us we see state-of-the-art production equipment and engaged employees, due to massive investments in people and equipment. We meet the production director Bo, who is ready to tell us everything about his experience of practising Strengths-based Lean.

\section{Becoming a competitive manufacturing plant}

Eight years earlier, it did not seem as if the manufacturing plant would survive in Denmark. Productivity was low and absenteeism was high. However, with help from a successful Appreciative Inquiry ( $\mathrm{Al}$ ) intervention, the future was rewritten and the plant established itself as a competitive company. They realised that they could position themselves as a competitive manufacturing plant in Denmark by becoming a ramp-up plant, i.e., a plant with high innovative capability that develops the production system when new products are introduced. The turn-around and Al intervention was described in details in a previous Al Practitioner article (Kongsbak, 2010).

In order to build innovative capability, the manufacturing plant embarked on a Lean journey, while also experimenting with Al and other strengths-based approaches. Consequently, a wide range of improvement methods and approaches were introduced. After a while, people became puzzled about how to integrate these approaches, since they often seemed to contradict each other. For example, whether 
Not only did they address the 'red' and deficit KPIs, they also inquired into those which were 'green' and performing well

\section{‘Every business challenge} is a people development opportunity.' Jeffrey Liker daily improvement activities should comprise identifying the three most important problems or to engage people in identifying success experiences to elevate? The following years turned out to be an experimental journey of figuring out how to combine the best of both worlds.

Both authors were involved in the journey for several years. Rasmus worked as an internal Lean consultant for three years and developed many of the practical solutions and methods that successfully combined Lean and strengths-based perspectives. David worked as a researcher and investigated how the innovative capability was developed over time at the manufacturing plant. One of the key figures on the journey was the production director, Bo Holm Jensen, who actively experimented with ways of developing Strengths-based Lean leadership. He was the ideal person to visit in order to articulate experiences and thoughts on Strengthsbased Lean, after being an active practitioner for five years.

The over-arching leadership focus: Long-term thinking and engagement We started the morning by attending the production directors' performance board meeting. Here, all associate managers reporting to the production director presented the status of all Key Performance Indicators (KPIs). However, this clearly was not your typical performance board meeting. The energy level was really, really high and everyone laughed several times during the ten minute meeting. Also, not only did they address the "red" and deficit KPIs and initiate corrective actions, they also inquired into those which were "green" and performing well, at first with a quick celebration and then by looking into whether they could learn anything from what was going well. You immediately noticed a close connection between the people and a willingness to help each other with whatever was necessary. And the meeting was over in just ten minutes.

We asked Bo how he thought the meeting went. Surprisingly, he was not really satisfied. He is clearly a results-focused manager and wanted faster improvement than the numbers currently showed. Yet, he used the board meeting as an occasion to energise everyone and initiate clever actions, rather than trying to force results too hastily. The most important task for a Strengths-based Lean leader is to stay focused on long-term thinking, he said. Continuous improvement is an endless journey for all of us, and leaders need to engage everyone into taking active part in the journey.

As a leader aiming for creating an improvement culture, there is a constant need to balance focus on driving results with focus on building capability in people and the organisation. Figure 1 illustrates this balance and four different leadership modes. For a mindful and aware leader, every situation requires conscious choice in terms of balancing the two dimensions. Most often, good leadership will find ways of moving further towards the upper right corner, for example by having the Jeffrey Liker quote in mind that "Every business challenge is a people development opportunity" (In conversation, 2013). 
Figure 1: Leadership modes for improvement (Adapted from Hansen, 2014).

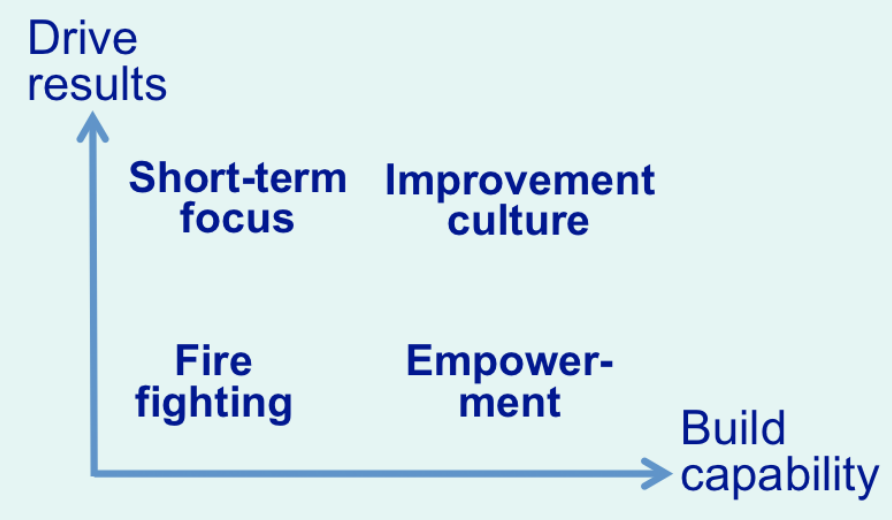

In the conversation, Bo also stressed how successful continuous improvement requires getting the best out of people. This comes from activating their particular individual strengths and passions. He described how fun is one of his most important leadership tools for helping people perform at their best. When you create a fun business environment, people are invited into taking initiative and using their creativity to drive results, he explains. Hamel's pyramid illustrates this hierarchy of human capabilities, as shown in Figure 2. The lower three levels can be demanded through management, but the upper three levels need to be earned through leadership. Bo describes that the strengths-based perspective really helps getting to the upper levels of Hamel's pyramid, due to its emphasis on individual strengths, connection to purpose and positive emotions.

We then asked about the three most important Strengths-based Lean practices.

\section{Strengths-based Gemba ${ }^{1}$ leadership}

The most important contribution that Lean has had on the daily leadership is that all managers now spend a majority of their time on the shop floor with the employees, collaborating on the top issues. The opportunities for developing people increase dramatically when the time spent on the shop floor increases because it enables new types of leadership behaviour.

An example of this is strength-spotting. We define an individual strength as a pattern of behaviour where the individual feels high energy and is competent. Examples could be: performing visual quality control, writing operational standards, training others, or systematic problem solving. When a manager spends time on the shop floor performing a process audit or participating in problem solving and is simultaneously strength-spotting, he or she has the opportunity to spot employees being competent and solving business critical tasks. This is an opportunity to help them identify what strengths they possess, should further develop and share with others. By helping people realise what their strengths are, and sharing this knowledge, the manager

1 A gemba walk is the term used to describe personal observation of work - where the work is happening. 
Figure 2: Hamel's pyramid of human capabilities (Hamel, 2010).
Managers now spend a majority of their time on the shop floor with the employees

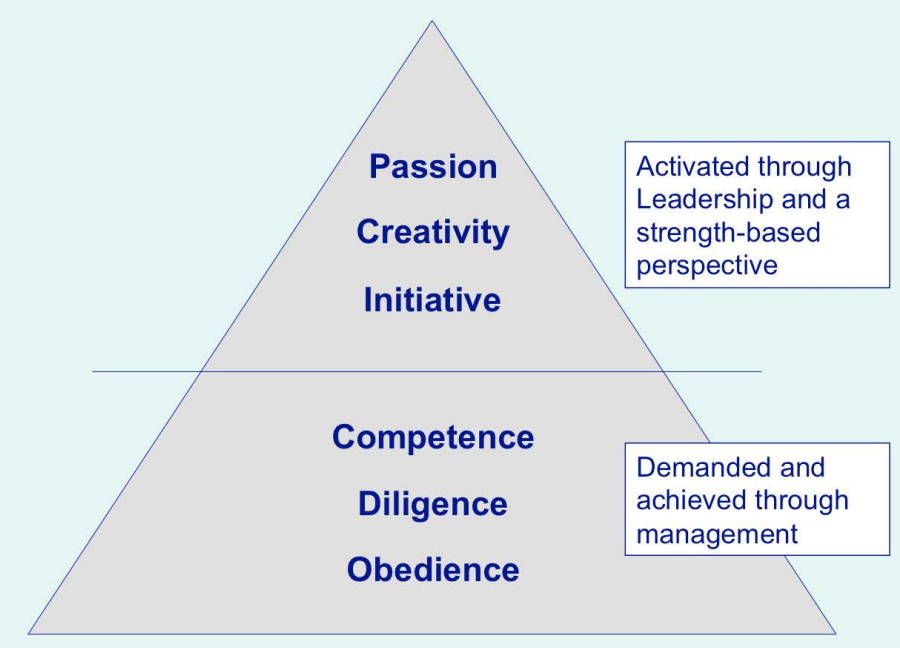

has further opportunities to organise people for better results and better capability building. As Marcus Buckingham notes in his 2005 paper on strengths-based leadership, "Good managers play checkers, great managers play chess."

Funny business - creating an atmosphere of positive emotions

Every month, as well as spontaneously from time to time, an event is carried out with the purpose of creating a fun and positive environment at work where people benefit from positive emotions and some extra energy to feed on. Examples are a big Christmas raffle, a group of samba dancers touring the facility, seven big cardboard "Where's Waldo?" figures hidden around the factory with inspiring questions, and funny videos at serious presentations. The value and seriousness of creating fun and positive emotions at work have been well described in the research by Barbara Fredrickson (1998) on positive emotions, which shows how the positive emotions broaden the human thought-and-action-repertoire and thereby enable more creative ideas and better connection to larger systems. To incorporate these Funny Business events as well as small daily practices with positive emotions are yet another way of reinforcing a creative and strength-focused improvement culture during daily management.

On a smaller scale, such as at the daily performance meetings, fun and positive emotions can elevate the human capabilities for the rest of the day.

\section{Learning systematically from positive deviance - success solving}

This practice was developed from an extraordinary Monday morning. The production director had his management team gathered at the daily performance meeting, reviewing the previous 24 hours. Normally Monday's performance is poor because all machines are started up after the weekend shutdown, and more often than not, one or more is not running and the KPI is red. But this Monday was special: all the 
'Funny business' event: daily reinforcement of the improvement culture

The production director first decided to just celebrate, then stopped to reflect and asked out loud: 'What is causing this best-in-class performance?'

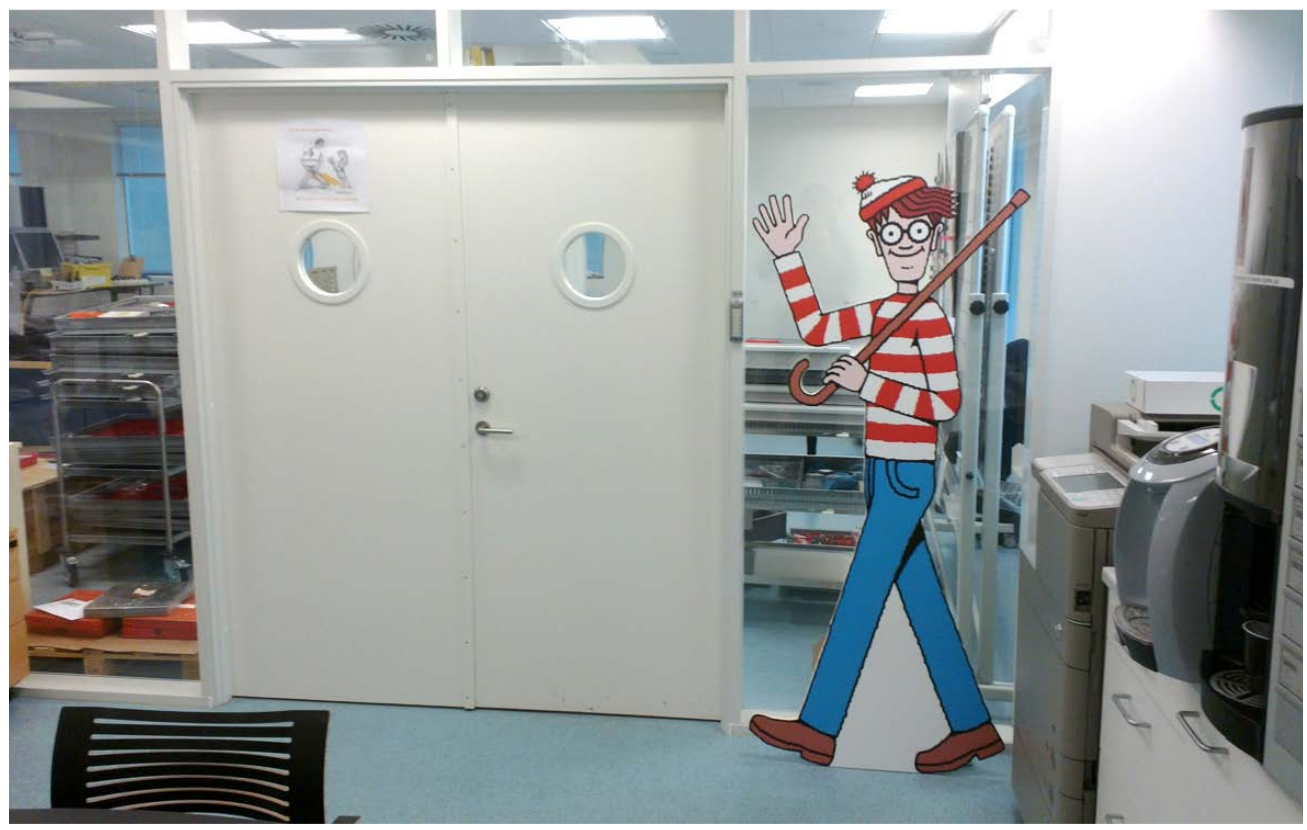

machines were up and running at full capacity. For once, the KPI was green on a Monday! The production director first decided to just celebrate, then stopped to reflect and asked out loud: "What is causing this best-in-class performance?"

The team leaders then looked at each other puzzled. After an awkward moment of silence, one of them answered: "We actually don't know why. We really don't have the knowledge necessary to answer that question!"

They then decided to systematically investigate what had gone particularly well, to solve the success. Success solving focuses on understanding an unexpected positive deviation from the expected with the purpose of learning what happened, and then changing the system permanently, making the success a new standard for the process. Much production equipment has a theoretical limit due to design constraints, but as a part of a socio-technical system where humans and equipment interact, it is often in the interaction between human and machine that the performance of the equipment is defined.

Problem solving is an effective and widely used tool for continuous improvement. However, the method can cause people to feel blamed and guilty, thereby harming the work environment. If businesses only focus on what is not working they miss the opportunity to learn from their success. Systematic learning from success enables repetition of what works and the solving process itself even reinforces the desired behaviour, as well as strengthens the work environment.

This is not a criticism of problem solving, because problem solving is both necessary and useful; by choosing to engage in problem solving an organisation signals to its employees that it is trying to improve their work environment by removing 
Five pieces of advice for implementing Strengths-

based Lean:

1. Get everyone on board on the Lean journey;

2. Resist the urge to copy-and-paste;

3. Stick to the appreciative paradigm;

4. Keep the long-term goal present;

5. Do not fall for external consultants who seem like they know what works. Bo Holm Jensen obstacles. Also, in some industries problems quite simply must be solved, e.g. in the pharmaceutical business or in ISO-certified companies.

As well, if organisations choose to focus only on the positive and suppress problems, it can create a tense work environment where difficult issues are not welcomed and employees can feel guilty when they bring a problem to attention. The point here is that an organisation should choose its improvement focus and apply the method that is useful for it, but they should do this knowing the consequences of the approach.

\section{Advice before embarking on the journey}

Finally, we asked Bo about what advice he would have given, if he had been able to send a letter to himself five years ago, knowing what he knows now.

Five pieces of advice I would give myself five years ago - Bo Holm Jensen

1. Get everyone on board on the Lean journey. Get the people along. You should continuously address "what's in it for me".

2. Resist the urge to copy-and-paste Toyota. We cannot do that. Have respect for differences in cultures. It requires good translation into your own context.

3. Stick to the appreciative paradigm. You can easily get dragged into the results mindset where you only focus on the short term.

4. Keep the long-term goal present at all times. Even when short-term results are completely red. Be careful about wanting to show that you are competent: Then you tend to shift to short-term thinking.

5. Do not fall for external consultants who seem like they know what works. You need to respect your own organisational culture. Do not throw everything overboard: when it doesn't work, you will need to repair everything afterwards.

We leave the factory and get on our bikes; we are in Denmark, after all. On our way home, filled with inspiration and reflections, we discuss what other organisations can learn from Bo and the other inspiring leaders at Novo Nordisk DMS. We end our discussions by pointing towards four key learning points:

1. Every organisation should be clear about what their particular strategy is and how it connects with the daily actions. If the strategy requires initiative, creativity and passion, you need leaders to step up and show the leadership that brings out those qualities in people. Do your actions help fulfil the longterm goals? Too often, the strategy is disconnected from daily business because there is no translation of the strategy to daily actions and mindset. 
2. The most important task of leadership is to bring everyone on board for the journey, in particular when continuous improvement is a strategic priority. This is a constant struggle and requires more than management systems. It requires leadership and support based on each individual's motivations to share ideas, express thoughts and do more than expected. A strengthsbased approach and true curiosity about what makes each individual tick, and what makes their energy levels high, is a powerful approach for creating an improvement culture. Especially when combined with clear communication of the strategy and why the employees' initiatives are important for the organisation.

3. Lean and the Toyota Way are wonderful sources of inspiration for creating great organisations. However, their most important lessons are not tools or technical systems: the most important lessons are the leadership style of supportive leadership on the shop floor and the constant focus on balancing capability building and results. Also, the improvement methodologies are quite powerful and worth inspiring you to create your own solutions and culture. Do not copy methods without understanding your own organisation's needs.

4. While red KPI's tend to draw attention, they may not be the best focus for enabling a continuous improvement culture or even the best targets for improvement activities. Sometimes they even drain energy or inhibit collaboration, which are critical factors for all organisations. More important, being problem focused can lure improvement initiatives into dead ends that are almost impossible to get out of, whereas a more deliberate focus on what to achieve and designing the desired future states is a much better approach. The strengths-based paradigm combined with Lean can create these shortcuts and energise people as a side effect!

\section{References}

Buckingham, M. (March, 2005) What Great Managers Do. Harvard Business Review. March, 70-79.

https://hbr.org/2005/03/what-great-managers-do

Fredrickson, B. (1998) What Good Are Positive Emotions? Review of General Psychology. 2, 300-319.

http://www.gruberpeplab.com/teaching/psych3131_spring2015/documents/15.1_ Fredrickson1998_WhatGoodarePositiveEmotions.pdf doi: http://dx.doi.org/10.1037/1089-2680.2.3.300

Hamel, G. (2007) The Future of Management. Massachusetts: Harvard Business Press.

Hansen, D. (2014) Decoding the Productivity Code - Towards an improvement theory for sustainable organizational performance. PhD Dissertation, Department of Management Engineering, Technical University of Denmark.

Kongsbak, H. (2010) From Crisis to Global Competitiveness. Al Practitioner, 12(3), 10-14. 


\section{IAPG Contacts and Al Practitioner Subscription Information}

\section{International Advisory Practitioners Group IAPG}

Members of the International Advisory Practitioners Group working with AIP to bring Al stories to a wider audience:

Dhruba Acharya, Nepal

Anastasia Bukashe, South Africa

Gervase Bushe, Canada

Sue Derby, Canada

Sara Inés Gómez, Colombia

Lena Holmberg, Sweden

Joep C. de Jong, Netherlands

Dorothe Liebig, Germany

John Loty, Australia

Sue James, Australia

Maureen McKenna, Canada

Liz Mellish, Australia

Dayle Obrien, Australia

Jan Reed, United Kingdom

Catriona Rogers, Hong Kong

Daniel K. Saint, United States

Marge Schiller, United States

Jackie Stavros, United States

Bridget Woods, South Africa

Jacqueline Wong, Singapore

Margaret Wright, United Kingdom

Disclaimer: Views and opinions of the writers do not necessarily reflect those of the publisher. Every effort is made to ensure accuracy but all details are subject to alteration. No responsibility can be accepted for any inaccuracies.

\author{
AlP Subscriptions \\ Individuals \\ Small organisations \\ Large organisations \\ http://www.aipractitioner.com/subscriptions
}

Issues and Articles

http://www.aipractitioner.com/issues

http://www.aipractitioner.com/articles

Change of subscriber details

http://www.aipractitioner.com/customer/account/login

Publication Advertising/Sponsorship

For the advertising rates, contact Anne Radford.

\section{Purpose of Al Practitioner}

This publication is for people interested in making the world a better place using positive relational approaches to change such as Appreciative Inquiry. The publication is distributed quarterly: February, May, August and November.

\section{Al Practitioner Editor/Publisher}

The editor-in-chief and publisher is Anne Radford. She is based in London and can be reached at editor@aipractitioner.com

The postal address for the publication is: 303 Bankside Lofts, 65 Hopton Street, London SE1 9JL, England.

Telephone: +44 (0)20 76339630

ISSN 17418224

Shelagh Aitken is the issue editor for Al Practitioner. shelagh@editorproofreader.co.uk

Al Practitioner (c) 2003-2015 Anne Radford

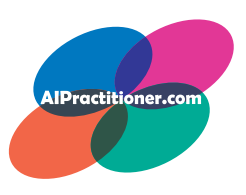

